\title{
Photocatalytic Process Optimization by Numerical Simulation Based on the Removal Efficiency of Carbamazepine under Different Operating Conditions
}

\author{
Lina Chen ${ }^{1}$, Qian Feng' ${ }^{*}$, Wen Yang ${ }^{3}$, Fangxiu Zhang ${ }^{4}$, Hubin Wei $^{5}$ \\ ${ }^{1}$ College of Agricultural Science and Engineering, Hohai University, Nanjing, 210098, China \\ ${ }^{2}$ College of Environment, Hohai University, Nanjing, 210098, China \\ ${ }^{3}$ Central and Southern China Municipal Engineering Design \& Research Institute Co. Ltd., Wuhan, 430000, China \\ ${ }^{4}$ Yellow River Institute of Hydraulic Research, Zhengzhou 450003, China \\ ${ }^{5}$ College of Public Administration, Nanjing Agricultural University, Nanjing, 210095, China
}

Received: 4 July 2020

Accepted: 26 September 2020

\begin{abstract}
Carbamazepine as a typical ingredient in pharmaceuticals and personal care products (PPCPs) cannot be removed by conventional wastewater treatment processes due to its biorefractory property. In this paper, the effects of photocatalytic operating conditions of wastewater treatment such as stirring speed, composite material dosage, light intensity, and irradiation time on the degradation of carbamazepine by ATC were studied. Considering the aspects of technology, economy, and environment, the photocatalytic process scheme was optimized for carbamazepine wastewater treatment using ATC. The results were analyzed and simulated by response surface methodology (RSM). The effects of various factors and their interactions on the treatment efficiency were analyzed using a multiple quadratic regression equation, by which the optimal process parameters and the process conditions with optimal response were achieved. Under low material dosage (less than $2 \mathrm{~g} / \mathrm{L}$ ), the pair-wise interactions among irradiation time, light intensity, and stirring speed contributed more to the treatment efficiency than medium ( $2 \mathrm{~g} / \mathrm{L}$ to $4 \mathrm{~g} / \mathrm{L}$ ) or high (more than $4 \mathrm{~g} / \mathrm{L}$ ) material dosage. The operation cost under low material dosage was relatively low, which shows that material cost is one of the most important factors in the actual photocatalytic process.
\end{abstract}

Keywords: $\mathrm{Ag}-\mathrm{TiO}_{2}$, carbamazepine, photocatalytic operating conditions, response surface methodology, photocatalytical degradation

*e-mail: xiaofq@hhu.edu.cn 


\section{Introduction}

Pharmaceuticals and personal care products (PPCPs) as a new form of environmental pollutant have become a focus of worldwide attention, like in Germany, Italy, America, Japan and so on [1-6]. Carbamazepine (CBZ), a type of PPCPs used in antiepileptic and mood stabilising clinical treatment, has been frequently detected in aquatic environments due to their extensive use and refractory properties [7-9]. However, the conventional processes of sewage treatment plants cannot effectively remove carbamazepine, mostly below $10 \%$ [10-12]. As a result, most of CBZ discharged into surface water environment and may cause potential harm to aquatic ecosystem and human health.

At present, the commonly used treatment methods for carbamazepine mainly include biodegradation, adsorption technology, membrane separation technology, and advanced oxidation processes. Yang et al. [13] studied the treatment of trace organic pollutants by white rot fungus and its lignin-modifying enzyme. The authors found that the degradation efficiencies towards carbamazepine were $31 \%$ and $15 \%$ respectively. Liu et al. [14] used graphene and carbon nanotubes to absorb ketoprofen, carbamazepine, and bisphenol A. They found that ionic strength had strong influence on the adsorption process, and the adsorption effect of graphene was better than that of carbon nanotubes. Cabrera-Lafaurie et al. [15] used modified clay to adsorb salicylic acid, chlorobeic acid, carbamazepine, and caffeine. Among those, the adsorption effect towards carbamazepine was the best, while that towards chlorobeic acid was the worst. However, the absorbents transform the substance from one phase to another rather than being completely eliminated. The energy consumption of adsorbent regeneration is large with the adsorption capacity reduced after regeneration. These factors lead to problems that hinder the use of the adsorption method. Lin et al. [16-17] have used nanofiltration and reverse osmosis technology to treat ibuprofen, carbamazepine, and triclosan. The results showed that the membrane technology had good treatment efficiency on these substances, but the investment and operation costs of membrane technology were high, and the system was prone to be blocked, necessitating high-level pretreatment and regular chemical cleaning. Problems of concentrate treatment also existed.

Advanced oxidation processes include Fenton oxidation, sonolysis, ozonation and photocatalysis as well as combinations. Photocatalysis is one of the technologies that has attracted great attention in the last years. Furthermore, this technology is particularly suitable for the treatment of relatively low water volumes with contaminants at low concentration. $\mathrm{TiO}_{2}$ has been the most widely used photocatalyst, due to its high activity, photostability, low cost, chemicalstability and biocompatibility [18]. The photocatalytic oxidation technology represented by $\mathrm{TiO}_{2}$ not only involves the advantages of oxidation and degradation but also decomposes trace organic intermediates in the water, and thus can be employed as a supplement and enhancement to the conventional treatment. In addition, photocatalytic technology can make full use of the continuously available solar energy which is costefficiency and environmentally friendly. The technology provides new methods and ideas for the removal of refractory organics and has good application prospects [19-20]. During the past two decades, researchers focused work on $\mathrm{TiO}_{2}$ modifications and novel efficient photocatalysts development $[9,18]$. Very recently, our group have used $\mathrm{Ag}$-doped $\mathrm{TiO}_{2}$ and chitosan (CTS) to prepare ATC $\left(\mathrm{Ag}-\mathrm{TiO}_{2}-\mathrm{CTS}\right)$, which has an improved effect on the adsorption and photocatalytic degradation efficiency towards carbamazepine. After treatment using ATC for $1 \mathrm{~h}$, the carbamazepine removal rate arrived at around $95 \%$, which is higher than the control test without catalyst (less than $2 \%$ removal efficiency). It has also found that the removal rate increases by about $45 \%$ compared with the usage of naked- $\mathrm{TiO}_{2}$. Even after repeated recycling, the degradation efficiency towards carbamazepine was maintained above $80 \%$.

Recent studies have shown that the removal efficiency of PPCPs is influenced by operating conditions [21]. However, at present, most researchers are concerned about how to prepare composite photocatalytic materials with high degradation efficiencies (pollutant removal rate) and stable performance (removal rate after recycling). Furthermore, there is little research on how to effectively apply the photocatalysis materials to sewage plants or water supply plants, and how the operating conditions of photocatalysis process affect the degradation efficiency towards PPCPs. In the present study, the composite photocatalytic material ATC was used to treat carbamazepine in water. The effects of operating conditions including stirring speed, material dosage, light intensity, and irradiation time on the degradation process of carbamazepine were studied. Finally, the optimal operating conditions for pollutant degradation were obtained by numerical simulation. This study can provide support for the practical application of ATC, and it can also provide reference for other high-performance photocatalytic materials under photocatalytic process.

\section{Material and Methods}

\section{Preparation of ATC}

For ATC $\left(\mathrm{Ag}^{-} \mathrm{TiO}_{2}-\mathrm{CTS}\right)$ material preparation, it needs three synthesis steps including three kind of solution produced. Synthesis step 1 , added $8 \mathrm{~g} \mathrm{TiO}_{2}$ into $300 \mathrm{~mL}$ distilled water in the beaker, then the mixed suspension solution A obtained after ultrasonication in $30 \mathrm{~min}$. Step 2 , mixed silver nitrate $(0.5 \% \mathrm{~W})$ into solution A got before and stirred for $30 \mathrm{~min}$. Then the mixture was treated with an ultraviolet lamp $(12 \mathrm{~W})$ 
for $180 \mathrm{~min}$. Finally, the mixed suspension solution B was obtained. Step 3, $3 \mathrm{~mL}$ hydrochloric acid and $8 \mathrm{~g}$ chitosan (CTS) were added into suspension solution B. Mixed the suspension last for $3 \mathrm{~h}$ until we obtain the mixed emulsion solution C. Last but not the least, the emulsion solution $\mathrm{C}$ was dropped into sodium hydroxide solution $(0.2 \mathrm{~mol} / \mathrm{L})$ using an automatic syringe. Standing overnight, clean the solution using distilled water until the $\mathrm{pH}$ of the cleaning solution was neutral. Put the solution into baker to dry at $60^{\circ} \mathrm{C}$, $\mathrm{Ag}-\mathrm{TiO}_{2}$-CTS (ATC) photocatalytic microspheres obtained.

\section{Reagents}

Carbamazepine $\left(\mathrm{C}_{15} \mathrm{H}_{12} \mathrm{~N}_{2} \mathrm{O}, 99 \%\right)$ used in the experiment was purchased from Sigma-Aldrich. Chitosan $\left(\left(\mathrm{C}_{6} \mathrm{H}_{11} \mathrm{NO}_{4}\right) \mathrm{N}\right.$ with a deacetylation degree of $80-95 \%$ ) was purchased from Sinopharm Chemical Reagents, and titanium dioxide $\left(\mathrm{TiO}_{2}, 80 \%\right.$ anatase and $20 \%$ rutile) was purchased from Evonik Degussa. Acetonitrile $\left(\mathrm{C}_{2} \mathrm{H}_{3} \mathrm{~N}\right.$, chromatographic purity) and acetic acid $\left(\mathrm{CH}_{3} \mathrm{COOH}\right.$, chromatographic purity) were purchased from Tedia. Sodium hydroxide $(\mathrm{NaOH}$, analytically pure), silver nitrate $\left(\mathrm{AgNO}_{3}\right.$, analytically pure), and nitric acid $\left(\mathrm{HNO}_{3}\right.$, analytically pure) were purchased from the Chengdu Kelong Chemical Reagent Plant, and hydrochloric acid ( $\mathrm{HCl}$, analytically pure) was purchased from Liyang Dongfang Reagent Co., Ltd.

\section{Removal of Carbamazepine}

The self-made photocatalytic device used in this experiment is shown in Fig. 1. The outer part is made of glass with a diameter of $13 \mathrm{~cm}$; the inner part is made of a glass container with a diameter of $9 \mathrm{~cm}$, and the UV lamp cover is made of quartz with a diameter of $5 \mathrm{~cm}$. The UV lamp (Philips PL-S) was set up with a main wavelength of $365 \mathrm{~nm}$. During operation, the prepared photocatalytic material was added into the simulated wastewater prepared in the laboratory. Aliquots of the samples were removed at given points in time. After filtering through a filter membrane $(0.45 \mu \mathrm{m})$, the concentration was determined by high performance liquid chromatography (1260, Agilent). To accurately study the effect of ATC on the photodegradation of carbamazepine, the initial concentration of carbamazepine was set to $5 \mathrm{mg} / \mathrm{L}$, which was selected according to the test concentration in the literature [3, 22-24].

To study the effects of operating conditions such as material dosage, stirring speed, light intensity, and irradiation time on the degradation process of carbamazepine, the variables were controlled when designing the experimental scheme under the above conditions.

Material dosage effect test: Added some ATC material, the dosages of ATC were 1, 2, 3, 4, 6, and $8 \mathrm{~g} / \mathrm{L}$, into $500 \mathrm{~mL}$ carbamazepine solution we

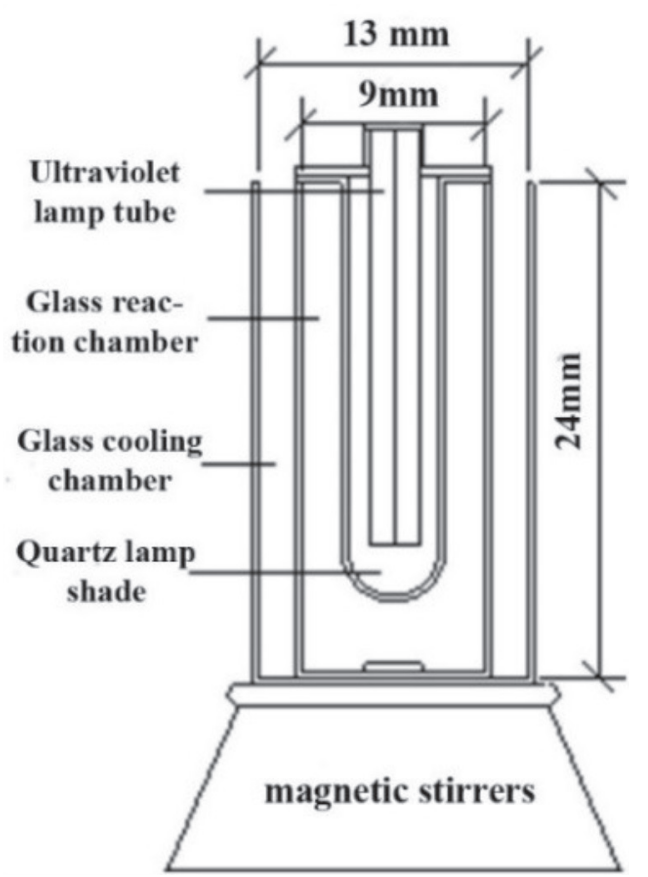

Fig. 1. Schematic diagram of the photocatalytic reaction device.

prepared before. Then, put the mixed solution in the photocatalytic reaction device. Irradiated under the UV light with an intensity of $20 \mathrm{~W}$, and the stirring speed was fixed at $150 \mathrm{rpm}$. After $1 \mathrm{~h}$ irradiation, the sample was collected through the filter membrane $(0.45 \mu \mathrm{m})$ for testing.

Stirring speed effect test: Added some ATC material, the dosage of ATC was $7 \mathrm{~g} / \mathrm{L}$, into $500 \mathrm{~mL}$ carbamazepine solution we prepared before. Then, put the mixed solution in the photocatalytic reaction device. Irradiated under the UV light with an intensity of $12 \mathrm{~W}$, and the stirring speed was adjusted to values of $0,50,100,150,200$, and $250 \mathrm{rpm}$. After $1 \mathrm{~h}$ irradiation, the sample was collected through the filter membrane $(0.45 \mu \mathrm{m})$ for testing.

Light intensity effect test: Added some ATC material, the dosage of ATC was $7 \mathrm{~g} / \mathrm{L}$, into $500 \mathrm{~mL}$ carbamazepine solution we prepared before. Then, put the mixed solution in the photocatalytic reaction device. Irradiated under the UV light with intensity set to $4 \mathrm{~W}, 8 \mathrm{~W}, 12 \mathrm{~W}, 16 \mathrm{~W}, 20 \mathrm{~W}$ and $24 \mathrm{~W}$, and the stirring speed was fixed at $150 \mathrm{rpm}$. After $1 \mathrm{~h}$ irradiation, the sample was collected through the filter membrane $(0.45 \mu \mathrm{m})$ for testing.

Irradiation time effect test: Added some ATC material, the dosage of ATC was $7 \mathrm{~g} / \mathrm{L}$, into $500 \mathrm{~mL}$ carbamazepine solution we prepared before. Then, put the mixed solution in the photocatalytic reaction device. Irradiated under the UV light with an intensity of $12 \mathrm{~W}$, and the stirring speed was fixed at $150 \mathrm{rpm}$. After $10 \mathrm{~min}, 20 \mathrm{~min}, 30 \mathrm{~min}, 40 \mathrm{~min}, 60 \mathrm{~min}, 80 \mathrm{~min}$, $120 \mathrm{~min}, 180 \mathrm{~min}$, and $240 \mathrm{~min}$, irradiation, the sample 
was collected through the filter membrane $(0.45 \mu \mathrm{m})$ for testing.

\section{Determination of Carbamazepine}

About the chromatography conditions of carbamazepine, an Agilent ZORBAX Exlipse XDB-C18 column $(150 \times 4.6 \mathrm{~mm}, 5 \mu \mathrm{m})$ was used. The mobile phase was acetonitrile: water $(60: 40, \mathrm{~V} / \mathrm{V})$; the flow rate was $1 \mathrm{~mL} / \mathrm{min}$; the column temperature was $20^{\circ} \mathrm{C}$; the detection wavelength was $285 \mathrm{~nm}$; the injection volume was $20 \mu \mathrm{L}$, and the retention time was $4 \mathrm{~min}$.

\section{Results and Discussion}

\section{Effect of ATC Dosage on the Removal Efficiency Towards Carbamazepine}

The effect of ATC dosage on the removal efficiency towards carbamazepine during the photocatalytic reaction in water is shown in Fig. 2. After $1 \mathrm{~h}$ irradiation with the light intensity $20 \mathrm{~W}$, the removal efficiency towards carbamazepine increased gradually with the ATC material dosage increasing. However, when the dosage of ATC was higher than $4 \mathrm{~g} / \mathrm{L}$, the removal efficiency did not increase in proportion with the increase in the ATC dosage. When the ATC dosages were $1,2,4$, and $8 \mathrm{~g} / \mathrm{L}$, the removal efficiencies towards carbamazepine were $32 \%, 56 \%, 80 \%$, and $82 \%$, respectively. The ATC dosage was increased by a factor of 2, 4, and 8, while the removal efficiency towards carbamazepine only increased by a factor of $1.75,2.5$, and 2.6. When the ATC dosage was higher than $4 \mathrm{~g} / \mathrm{L}$, the removal efficiency tended to reach a plateau with the increasing dosage.

Clearly, the ATC dosage had a significant impact on the photocatalytic oxidation of carbamazepine. In general, when the ATC dosage was low, the contact probability of target pollutants and catalysts increased with the increase in the catalyst dosage. Also, due to

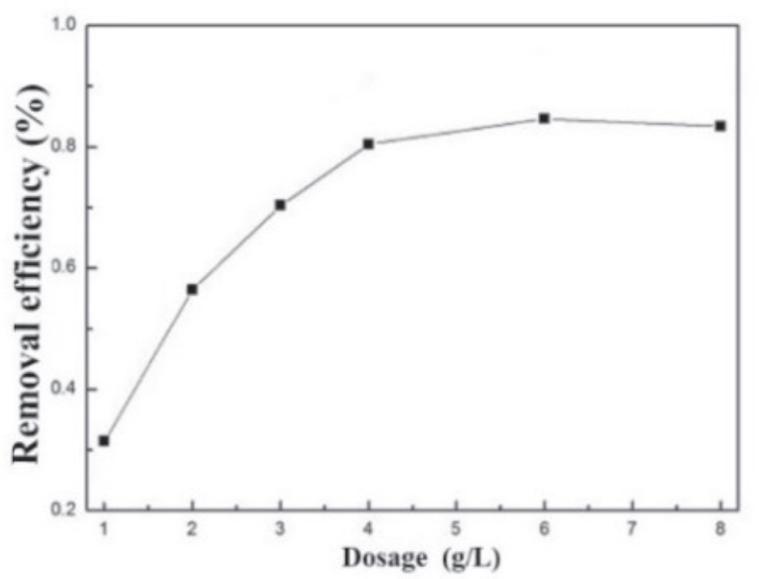

Fig. 2. Effect of dosage on the removal efficiency towards CBZ. the increasing catalyst amount, more oxidation groups were produced under the same irradiation conditions. All of these factors can promote the photocatalytic oxidation and improve the removal efficiency towards carbamazepine. However, when the dosage of ATC exceeded a certain concentration range (more than $4 \mathrm{~g} / \mathrm{L}$ ), the removal efficiency was restricted. The removal efficiency reduces by the screening effect once the further increment of dosage beyond the optimum amount $[25,26]$. At this moment, the light energy can not be available adequately due to the scattering phenomena appeared [27]. It makes active sites on the surface of the ATC do not generate more $\mathrm{e}-/ \mathrm{h}+$. Therefore, increase in degradation efficiency rate does not occur.

\section{Effect of Stirring Speed on the Removal Efficiency Towards Carbamazepine}

The stirring speed directly affected the mixing degree of ATC and carbamazepine in water as well as the degradation effect. Fig. 3 shows the removal efficiency towards carbamazepine during the photocatalytic reaction after $1 \mathrm{~h}$ irradiation at different stirring speeds with the light intensity $12 \mathrm{~W}$.

In general, with increasing stirring speed, the removal efficiency towards carbamazepine increased rapidly at first, then rose slightly and maintained at a relatively stable level. The removal efficiency towards carbamazepine in water was $64 \%$ with the light intensity $12 \mathrm{~W}$ for $1 \mathrm{~h}$ without stirring (the stirring speed was 0 ). When the stirring speed increased to $100 \mathrm{rpm}$, the removal efficiency towards the pollutants in water increased by $15 \%$, and the removal efficiency towards carbamazepine in water was close to $80 \%$. With the increase in stirring speed, the diffusion rate of carbamazepine to the surface of ATC was increased, and the reaction efficiency was improved. However, when the stirring speed was higher than $100 \mathrm{rpm}$, although the removal efficiency towards carbamazepine fluctuated slightly, it tended to be stable on the whole,

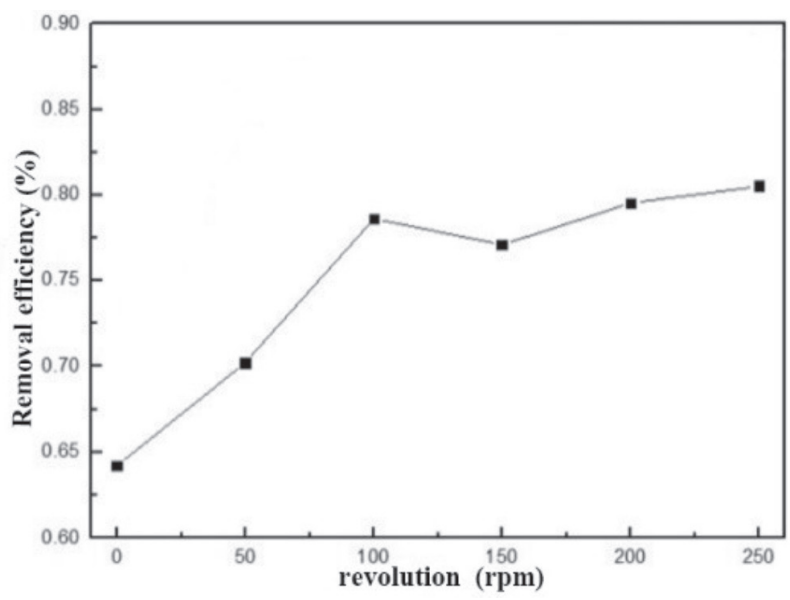

Fig. 3. Effect of stirring speed on the removal efficiency towards CBZ. 
and further increases in the stirring speed did not significantly change the photocatalytic effect of ATC towards removal of carbamazepine. With the increasing stirring speed, more and more carbamazepine rely on the ATC surface, but available active sites on the ATC surface are limited. This is should be the main reason why the stirring speed does not influence on the removal of the pollutant at high speed (more than $100 \mathrm{rpm})$.

\section{Effect of Light Intensity on the Removal Efficiency Towards Carbamazepine}

With an increase in light intensity, from $4 \mathrm{~W}$ to $24 \mathrm{~W}$, the removal efficiency towards carbamazepine during the $1 \mathrm{~h}$ photocatalytic reaction in water increased as Fig. 4. Light intensity increasing improved the excitation energy, thus increasing the concentration of oxidation groups in the solution and improving the degradation effect of ATC towards carbamazepine. When the light intensity was $4 \mathrm{~W}$, the removal efficiency towards carbamazepine was $73 \%$; when the light intensity was increased to $24 \mathrm{~W}$, the removal efficiency towards carbamazepine was $83 \%$. The removal efficiency of carbamazepine increased by $10 \%$ when the light intensity was increased by a factor of

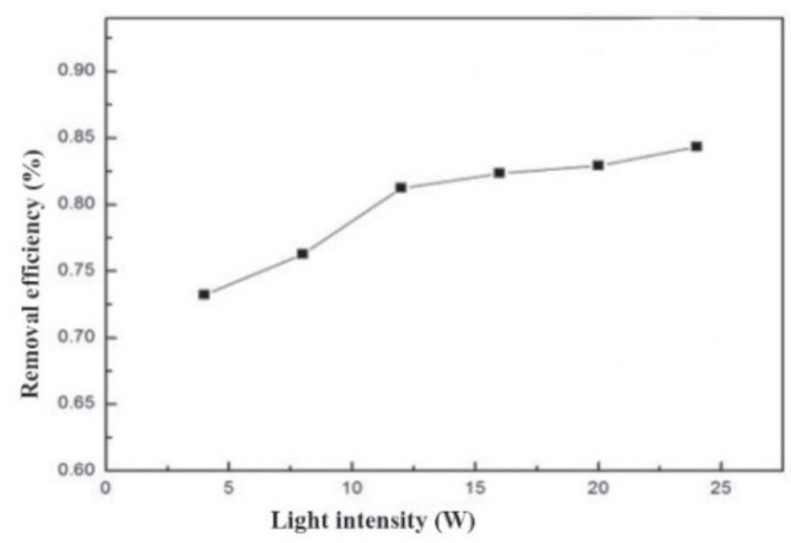

Fig. 4. Effect of light intensity on the removal efficiency towards CBZ.

Table 1. Ultraviolet intensity and removal efficiency under different light intensity.

\begin{tabular}{|c|c|c|}
\hline $\begin{array}{c}\text { Light inten- } \\
\text { sity (w) }\end{array}$ & $\begin{array}{c}\text { Ultraviolet intenstiy } \\
\text { (einsteins/s) }\end{array}$ & $\begin{array}{c}\text { Removal efficiency } \\
(\%)\end{array}$ \\
\hline 4 & $8.47 \mathrm{E}-06$ & 73.22 \\
\hline 8 & $1.77 \mathrm{E}-05$ & 76.30 \\
\hline 12 & $2.82 \mathrm{E}-05$ & 81.24 \\
\hline 16 & $3.81 \mathrm{E}-05$ & 82.33 \\
\hline 20 & $4.8 \mathrm{E}-05$ & 82.95 \\
\hline 24 & $5.86 \mathrm{E}-05$ & 84.36 \\
\hline
\end{tabular}

6 with the ultraviolet intensity range from $8.47 \mathrm{e}-06$ to 5.86e- 05 , see Table 1 .

Under dark conditions, the removal efficiency towards carbamazepine by ATC was about $8 \%$. No oxidation groups could be produced in the reaction system, and the degradation and removal of carbamazepine by ATC were mainly realized by adsorption. Clearly, for the removal of carbamazepine from water, the oxidation groups produced from photocatalytic excitation play an important role in the degradation of carbamazepine, and the effect of photocatalytic oxidative degradation is stronger than that of adsorption. However, excessive light intensity would affect the photocatalytic activity due to recombination of the electron-hole pair with the increment of temperature from the light [28].

\section{Effect of Irradiation Time on the Removal Efficiency Towards Carbamazepine}

The effect of irradiation time on degradation of carbamazepine by ATC under light intensity 12 and stirring speed $150 \mathrm{rpm}$ is shown in Fig. 5. In the initial $60 \mathrm{~min}$, the removal efficiency towards carbamazepine increased rapidly, and the removal efficiency towards carbamazepine reached $79 \%$. Then, in the $3 \mathrm{~h}$ after the initial $60 \mathrm{~min}$, the removal rate towards carbamazepine gradually decreased. Although the removal efficiency towards carbamazepine increased to nearly $99 \%$, it only increased by $20 \%$ compared with the initial $60 \mathrm{~min}$. Generally, the degradation of carbamazepine by ATC mainly occurred during the initial $60 \mathrm{~min}$ of the photocatalytic reaction, and then although the degradation slowed, the reaction continued, and the removal efficiency was close to $99 \%$ after $240 \mathrm{~min}$ of continuous irradiation.

In addition, carbamazepine degradation kinetics can be described by the first-order kinetic. The first-order kinetic constant is $0.046 \mathrm{~s}^{-1}\left(\mathrm{R}^{2}=0.932\right)$. This value is higher than the kinetic constant for degradation without catalyst $\left(0.0002 \mathrm{~s}^{-1}, \mathrm{R}^{2}=0.852\right)$.

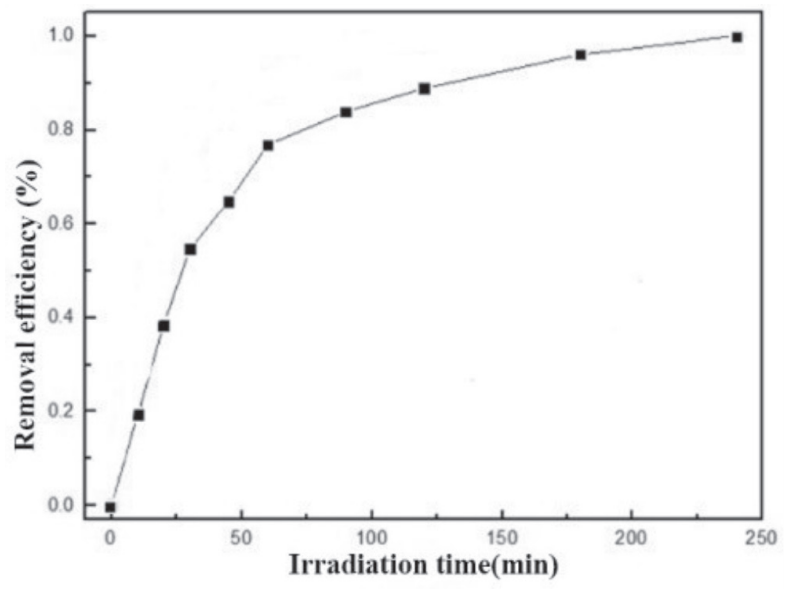

Fig. 5. Effect of irradiation time on the removal efficiency towards CBZ. 


\section{Optimization of Process Parameters}

In summary, the stirring speed, material dosage, light intensity, and irradiation time all affected the degradation and removal of carbamazepine by ATC. Different reaction conditions not only changed the degradation effect towards target pollutant but also affected the cost of wastewater treatment. Therefore, considering the technical feasibility, economic feasibility, and environmental friendliness of the treatment process, the removal scheme for target pollutants in wastewater by ATC was optimized to further improve the practical application and promotion of the treatment process.

In this study, RSM [29, 30], which is commonly used in the chemical industry, in biosynthesis, and in environmental engineering, was used to analyze and simulate the experimental results. A multiple quadratic regression equation was used to analyze the influence of various factors and their interactions on the response variable. Through the analysis of the model equation, the optimal process parameters were obtained to achieve the optimal conditions.

The test design and data processing software Design-Expert 7.0 was used. The multiple regression equation (model) fitted by the least squares method was

$$
Y \times 100 \%=B_{0}+\sum_{i=1}^{n} B_{i} X_{i}+\sum_{i=1}^{n} B_{i i} X_{i}^{2}+\sum_{i=1, j=1}^{n} B_{i j} X_{i} X_{j}+e
$$

...where $\mathrm{Y}$ is the amount of pollutant removed; $\mathrm{B}_{0}$ is the intercept, which is a constant; $\mathrm{B}_{\mathrm{i}}$ is the linear coefficient; $\mathrm{B}_{\mathrm{ij}}$ is the coefficient of the interaction; Bii is the quadratic term coefficient; and e is the error.

The experimental results were analyzed by analysis of variance (ANOVA), and by the correlation coefficient $\left(\mathrm{R}^{2}\right)$, homogeneity test of variance (F-value and Prob $>F$ ) between global variables and corresponding parameters, and signal-to-noise ratio (Adeq Precision). ANOVA was used to determine the goodness of fit of the fitting equation. If the fit was good, the interactions were analyzed according to the fitting equation, and the optimal conditions of the target expectation were obtained, or at least the optimal conditions within the expected range were obtained.

With the stirring speed, material dosage, light intensity, and irradiation time as variable factors, the removal amount was adopted as the objective function, and a multiple regression equation between removal amount and stirring speed, material dosage, light intensity, and irradiation time could be obtained by fitting the response surface. However, the selection of the values of these four factors often affects the use of materials and operating costs. Therefore, a cost function was obtained by synthetically analyzing the cost reflected by the four factors: stirring speed, material dosage, light intensity, and irradiation time.

$$
\mathrm{R}=\mathrm{Y} / \mathrm{W}
$$

Here, $\mathrm{R}$ is the amount of pollutant removed per unit cost $(\mathrm{mg} /$ dollar); $\mathrm{Y}$ is the amount of pollutant removed (mg), $\mathrm{Y}>4$ (to ensure a removal efficiency of $80 \%$ ); $\mathrm{W}$ is cost of pollutant removal (dollar).

Taking $\mathrm{R}$ as the objective function, an optimization program was written using VB 6.0 software. The program optimized $\mathrm{R}$ within a given range of stirring speed, material dosage, light intensity, and irradiation time. The corresponding operating conditions of each factor under the optimal conditions were obtained, and these conditions could be used to guide follow-up research and practical operations.

\section{Selection of Test Factor Level and Establishment of Response Equation}

According to the above discussion, the test factors were determined as material dosage, irradiation time, light intensity, and stirring speed. The level of each factor was determined according to the single-factor tests. The center points, high levels, and low levels of the parameters were determined near the optimal conditions obtained from each single-factor test. Values were assigned, and $-1,0,+1$ represented low, medium, and high levels, respectively. The value of $\alpha$ was set to 2 to determine the two extreme levels $(-\alpha$ and $+\alpha)$. Table 2 shows the determination of test factors and levels. Here, for description in convenient, use A, B, C, D to stand for material dosage, irradiation time, light intensity and stirring speed respectively.

The test design scheme and results for carbamazepine are shown in Table 3.

According to the test data, the regression equation of the response surface of carbamazepine in coded form is:

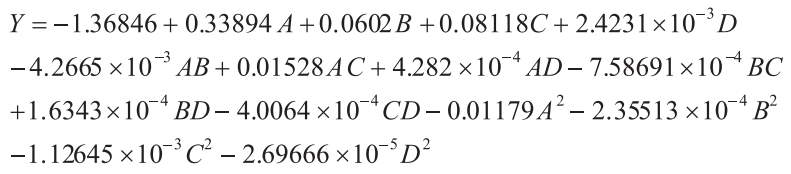

...where, A, B, C, D stands for the values of material dosage, irradiation time, light intensity and stirring speed respectively.

Table 2. Test factors for the response surface of carbamazepine.

\begin{tabular}{|c|c|c|c|c|c|c|}
\hline \multirow{2}{*}{ Factor } & \multirow{2}{*}{ Variable } & \multicolumn{5}{|c|}{ Level } \\
\cline { 3 - 8 } & & -2 & -1 & 0 & 1 & 2 \\
\hline Dosage (g/L) & $\mathrm{A}$ & 1 & 3 & 5 & 7 & 9 \\
\hline Irradiation time (min) & $\mathrm{B}$ & 15 & 30 & 45 & 60 & 75 \\
\hline Light intensity (W) & $\mathrm{C}$ & 4 & 8 & 12 & 16 & 20 \\
\hline Stirring speed (rpm) & $\mathrm{D}$ & 0 & 50 & 100 & 150 & 200 \\
\hline
\end{tabular}


Table 3. Test design and test results of the response surface for carbamazepine.

\begin{tabular}{|c|c|c|c|c|c|c|c|}
\hline \multirow{2}{*}{$\begin{array}{c}\text { Standard } \\
\text { number }\end{array}$} & \multirow{2}{*}{$\begin{array}{l}\text { Operation } \\
\text { number }\end{array}$} & \multirow{2}{*}{ Dosage $(\mathrm{g} / \mathrm{L})$} & \multirow{2}{*}{$\begin{array}{l}\text { Irradiation } \\
\text { time (min) }\end{array}$} & \multirow{2}{*}{$\begin{array}{l}\text { Light intensity } \\
\text { (W) }\end{array}$} & \multirow{2}{*}{$\begin{array}{l}\text { Stirring speed } \\
\quad(\mathrm{rpm})\end{array}$} & \multicolumn{2}{|c|}{ Removal amount } \\
\hline & & & & & & Actual value & Predicted value \\
\hline 9 & 1 & 3 & 30 & 8 & 150 & 1.491075 & 1.718358 \\
\hline 6 & 2 & 7 & 30 & 16 & 50 & 3.661183 & 3.610422 \\
\hline 23 & 3 & 5 & 45 & 12 & 0 & 2.518597 & 2.622672 \\
\hline 1 & 4 & 3 & 30 & 8 & 50 & 1.785344 & 1.717142 \\
\hline 4 & 5 & 7 & 60 & 8 & 50 & 2.570879 & 3.001131 \\
\hline 30 & 6 & 5 & 45 & 12 & 100 & 3.111384 & 3.064083 \\
\hline 8 & 7 & 7 & 60 & 16 & 50 & 4.102205 & 3.765545 \\
\hline 18 & 8 & 9 & 45 & 12 & 100 & 3.775691 & 3.896353 \\
\hline 27 & 9 & 5 & 45 & 12 & 100 & 3.133077 & 3.064083 \\
\hline 11 & 10 & 3 & 60 & 8 & 150 & 2.866643 & 3.057837 \\
\hline 7 & 11 & 3 & 60 & 16 & 50 & 2.799788 & 2.841785 \\
\hline 19 & 12 & 5 & 15 & 12 & 100 & 1.891845 & 2.10482 \\
\hline 10 & 13 & 7 & 30 & 8 & 150 & 2.737885 & 2.836418 \\
\hline 26 & 14 & 5 & 45 & 12 & 100 & 2.780488 & 3.064083 \\
\hline 12 & 15 & 7 & 60 & 8 & 150 & 3.843192 & 3.663917 \\
\hline 25 & 16 & 5 & 45 & 12 & 100 & 3.254867 & 3.064083 \\
\hline 17 & 17 & 1 & 45 & 12 & 100 & 2.007818 & 1.854533 \\
\hline 24 & 18 & 5 & 45 & 12 & 200 & 3.102905 & 2.966162 \\
\hline 20 & 19 & 5 & 75 & 12 & 100 & 3.845065 & 3.599422 \\
\hline 28 & 20 & 5 & 45 & 12 & 100 & 3.040752 & 3.064083 \\
\hline 13 & 21 & 3 & 30 & 16 & 150 & 2.145116 & 1.855386 \\
\hline 16 & 22 & 7 & 60 & 16 & 150 & 3.899195 & 4.107819 \\
\hline 21 & 23 & 5 & 45 & 4 & 100 & 2.743535 & 2.541269 \\
\hline 3 & 24 & 3 & 60 & 8 & 50 & 2.562128 & 2.566331 \\
\hline 14 & 25 & 7 & 30 & 16 & 150 & 3.575983 & 3.462406 \\
\hline 15 & 26 & 3 & 60 & 16 & 150 & 2.852848 & 3.012779 \\
\hline 22 & 27 & 5 & 45 & 20 & 100 & 3.273114 & 3.442711 \\
\hline 2 & 28 & 7 & 30 & 8 & 50 & 2.933147 & 2.663922 \\
\hline 5 & 29 & 3 & 30 & 16 & 50 & 2.104705 & 2.174682 \\
\hline 29 & 30 & 5 & 45 & 12 & 100 & 3.065476 & 3.064083 \\
\hline
\end{tabular}

The test design scheme and results for carbamazepine are shown in Table 3.

Significance Analysis of the Fitting Equation

The goodness of fit test of the model is an indispensable step in data analysis. If a model function with a poor fit is adopted, it will produce deviations or even yield wrong results. The results of the ANOVA for the model are shown in Table 4.

The variance and residuals of the model were divided by the corresponding degrees of freedom to obtain the respective mean squared errors. The ratio of the two mean squared errors is the F-value. The $\mathrm{F}$ value of the carbamazepine model was $12.38>\mathrm{F}(0.05)=2.42$, which indicates that the model had a high level of significance and the confidence was greater than $95 \%$. The Prob $>F$ was less than 0.0001 , further indicating that the model had a high significance level. The model would deviate due to noise [31, 32] with a probability of only $0.01 \%$. The correlation coefficient 
Table 4. ANOVA of the response model for carbamazepine.

\begin{tabular}{|c|c|c|c|c|c|c|}
\hline Source & Sum of squares & df & Mean square & F-value & $p$-value of Prob $>F$ & \\
\hline Model & 12.12 & 14 & 0.87 & 12.38 & $<0.0001$ & Significant \\
\hline Residual & 1.05 & 15 & 0.070 & & & \\
\hline Pure Error & 0.12 & 5 & 0.025 & & & \\
\hline Cor Total & 13.16 & 29 & & & & \\
\hline \multicolumn{2}{|c|}{ Std. Dev } & 0.26 & \multicolumn{2}{|c|}{ R-squared } & 0.9204 & \\
\hline \multicolumn{2}{|c|}{ Mean } & 2.92 & \multicolumn{2}{|c|}{ Adj R-squared } & 0.8461 & \\
\hline \multicolumn{2}{|c|}{ Adeq Precision } & 12.791 & & & & \\
\hline
\end{tabular}

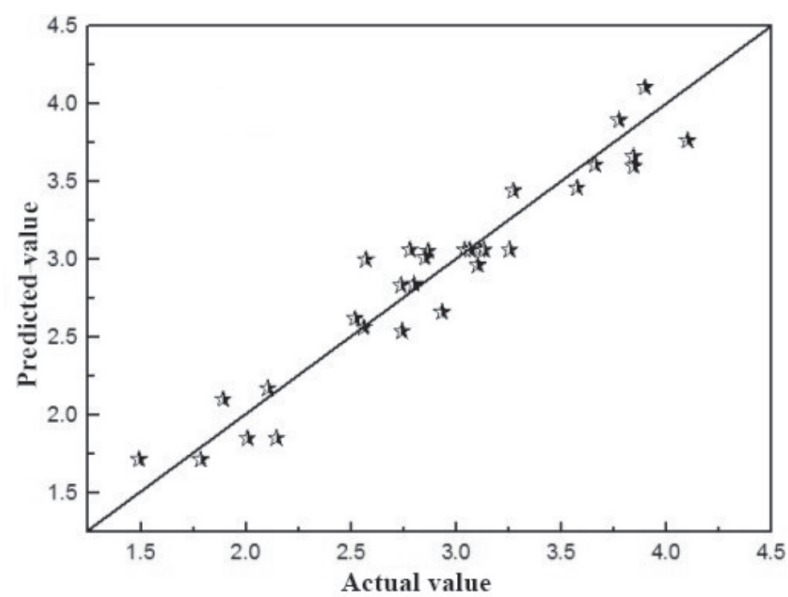

Fig. 6. The predicted value and actual value of the CBZ model.

of carbamazepine was $\mathrm{R}^{2}=0.9204$, and the correlation was greater than $90 \%$. The Adeq Precision of the carbamazepine model was 12.791, which was much higher than 4 . This shows that the model was suitable and could be applied.

It can be seen from the figure of predicted and actual values that the actual values of removal efficiency towards carbamazepine were almost all within the range of predicted values $\pm \alpha=0.05$, and the correlation between predicted values and actual values was very

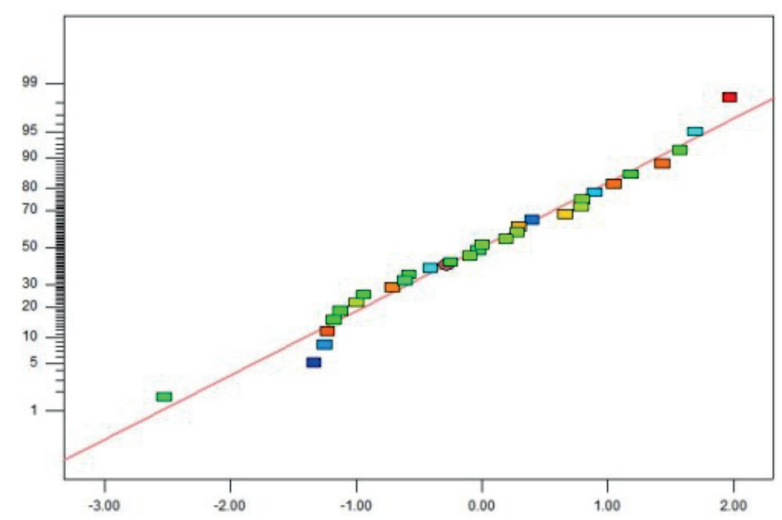

Fig. 7. Normal distribution of probability in the CBZ model. good. In the residual graphs shown from Fig. 7 to Fig. 9, except for the large errors of the extreme values added at the endpoints of each factor in the experimental design, the residuals of other points were all within 0.050 , and they were nearly normally distributed. The error of the model was mainly system error that was within the controllable range. The above ANOVA indicated that the model can be used to effectively simulate and predict the removal amount of carbamazepine by ATC.

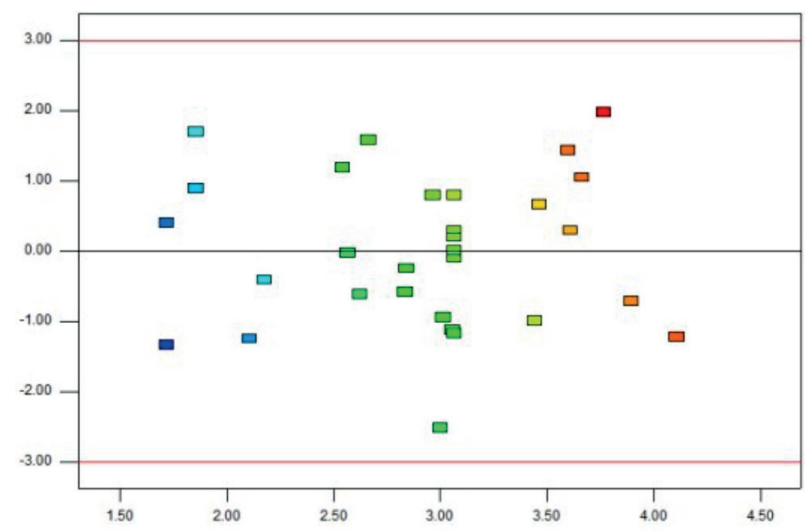

Fig. 8. Residuals plot for the CBZ model.

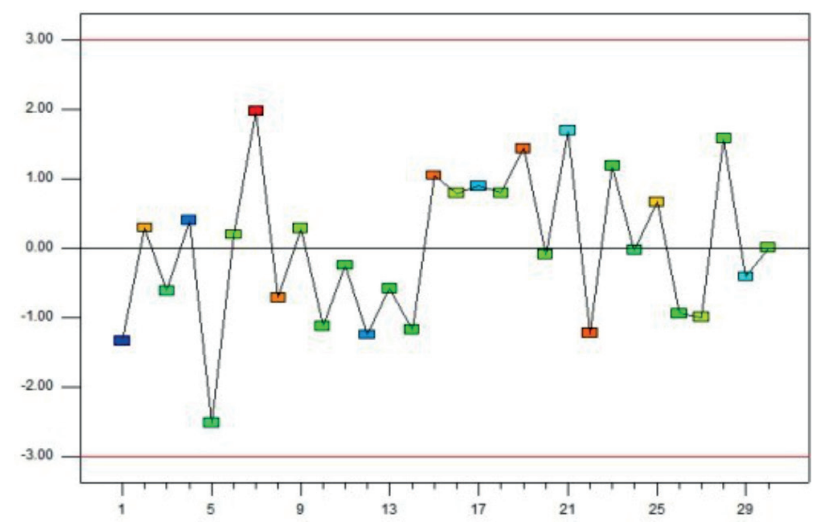

Fig. 9. Residuals plot for the CBZ model in sequential order. 
Table 5. Cost analysis.

\begin{tabular}{|c|c|c|c|c|c|}
\hline & Content & Amount & \multicolumn{2}{|c|}{ Unit cost } & Cost \\
\hline \multirow{11}{*}{ Material cost } & Chitosan & $1 \mathrm{~kg}$ & \multicolumn{2}{|c|}{$13.44 \$ / \mathrm{kg}$} & \multirow{11}{*}{$0.05 \$ / g$} \\
\hline & Titanium oxide & $1 \mathrm{~kg}$ & \multicolumn{2}{|c|}{$63.65 \$ / \mathrm{kg}$} & \\
\hline & Silver nitrate & $40 \mathrm{~g}$ & \multicolumn{2}{|c|}{$33.95 \$ / 100 \mathrm{~g}$} & \\
\hline & Nitric acid & $375 \mathrm{ml}$ & \multicolumn{2}{|c|}{$2.12 \$ / 500 \mathrm{ml}$} & \\
\hline & Water & $1250 \mathrm{~L}$ & \multicolumn{2}{|c|}{$0.40 \$ / \mathrm{m} 3$} & \\
\hline & Sodium hydroxide & $1250 \mathrm{~g}$ & & & \\
\hline & Ultrasonication & $62.5 \mathrm{~h}^{*}$ & & \multirow{5}{*}{$0.07 \$ / \mathrm{kw} \mathrm{h}$} & \\
\hline & Ultraviolet cost & $370 \mathrm{~h}$ & & & \\
\hline & Injection pump & $750 \mathrm{~h}$ & & & \\
\hline & Drying & $73 h^{* 1}$ & & & \\
\hline & Stirring & $12 \mathrm{~h} * 1$ & & & \\
\hline \multirow{4}{*}{ Operating cost } & Dosage & \multicolumn{2}{|c|}{ A } & & \\
\hline & Irradiation time & \multicolumn{2}{|c|}{ B } & & \\
\hline & Light intensity & \multicolumn{2}{|c|}{$\mathrm{C}$} & & \\
\hline & Stirring speed & \multicolumn{2}{|c|}{ D } & & \\
\hline
\end{tabular}

\section{Establishment of Model on Treatment Cost and Unit Cost}

The cost of sewage treatment mainly consists of electricity consumption, chemical reagent costs, maintenance costs, material costs, and control management. Among these, electricity consumption and chemical reagent costs are the most-needed expenses in the production process, and they account for a large proportion. They must be strictly controlled in the production process to effectively reduce the cost. In actual operation, it is necessary to integrate all factors to find the optimal operation mode that not only meets the appropriate requirements but also reduces the operation cost.

Table 5 shows a comprehensive analysis of the cost under the operating conditions in the laboratory, and the following cost model (W) was obtained.

$$
W=0.01 A+1.9 \times 10^{-6} B C+1.1 \times 10^{-6} B D
$$

...where, A, B, C, D stands for the values of material dosage, irradiation time, light intensity and stirring speed respectively. The values for different factor is $1 \leq \mathrm{A} \leq 9,15 \leq \mathrm{B} \leq 75,4 \leq \mathrm{C} \leq 20$ and $0 \leq \mathrm{D} \leq 200$.

The objective function is obtained based on the above analysis:

$$
\mathrm{R}=\mathrm{Y} / \mathrm{W}
$$

Here, $\mathrm{R}$ is the amount of pollutant removed per unit cost (mg/dollar); $\mathrm{Y}$ is the amount of pollutant removed (mg), $\mathrm{Y}>4$ (to ensure a removal efficiency of $80 \%$ ); $\mathrm{W}$ is cost of pollutant removal (dollar).

Using VB6.0 program software to optimize the objective function $\mathrm{R}$, the results for carbamazepine were $\mathrm{A}($ material dosage $)=5, \mathrm{~B}($ irradiation time $)=75, \mathrm{C}($ light intensity $)=8$, and (D stirring speed $)=200$; the removal efficiency was $80 \%$, and $\mathrm{R}=1.105$. Combinations near the optimal condition were selected as shown in Table 6. In the actual operation process, it is necessary to select an appropriate combination as a reference for operating conditions according to the actual situation.

\section{Surface Analysis of Photocatalysis of Carbamazepine by ATC}

According to the response surface and its corresponding contour map based on the model of pollutant removal amount per unit cost, the effects of the interactions between any two experimental factors on the pollutant removal amount per unit cost can be evaluated, and the best range of each factor can be determined. The shape of the contour can reflect the strengths of the effects of the interactions between various factors.

Fig. 10 shows the surface and contour map of the effects of the interactions among stirring speed, material dosage, light intensity, and irradiation time on the removal amount of carbamazepine per unit cost. It can be seen that the removal amount of carbamazepine per unit cost decreased with an increase in dosage when other parameters were kept constant. When the dosage increased from $1 \mathrm{~g} / \mathrm{L}$ to $2 \mathrm{~g} / \mathrm{L}$, the $\mathrm{R}$ value decreased sharply. When the dosage increased from $2 \mathrm{~g} / \mathrm{L}$ to 
Table 6. Combination of operating conditions.

\begin{tabular}{|c|c|c|c|c|c|c|}
\hline No. & Dosage $(\mathrm{g} / \mathrm{L})$ & Irradiation time (min) & Light intensity (W) & Stirring speed (rpm) & Removal efficiency (\%) & $\mathrm{R}$ \\
\hline 1 & 5 & 75 & 8 & 200 & 80 & 1.105 \\
\hline 2 & 6 & 65 & 20 & 100 & 80 & 0.939 \\
\hline 3 & 6 & 65 & 20 & 150 & 81 & 0.944 \\
\hline 4 & 6 & 70 & 12 & 200 & 80.6 & 0.934 \\
\hline 5 & 6 & 70 & 16 & 150 & 80.6 & 0.940 \\
\hline 6 & 6 & 70 & 16 & 200 & 81.2 & 0.941 \\
\hline 7 & 6 & 70 & 20 & 100 & 80.6 & 0.943 \\
\hline 8 & 6 & 70 & 20 & 150 & 82 & 0.957 \\
\hline 9 & 6 & 70 & 20 & 200 & 81.2 & 0.939 \\
\hline 10 & 6 & 75 & 4 & 200 & 80.2 & 0.928 \\
\hline 11 & 6 & 75 & 8 & 200 & 82 & 0.948 \\
\hline 12 & 6 & 75 & 12 & 150 & 80 & 0.931 \\
\hline 13 & 6 & 75 & 12 & 200 & 83 & 0.931 \\
\hline 14 & 6 & 75 & 16 & 150 & 82 & 0.953 \\
\hline 15 & 6 & 75 & 16 & 200 & 83.4 & 0.963 \\
\hline 16 & 9 & 75 & 20 & 100 & 80.8 & 0.944 \\
\hline 16 & 6 & 75 & 20 & 150 & 83.2 & 0.966 \\
\hline 18 & 6 & 75 & 20 & 200 & 83 & 0.958 \\
\hline
\end{tabular}

$4 \mathrm{~g} / \mathrm{L}$, the $\mathrm{R}$ value decreased gradually. When the dosage was greater than $4 \mathrm{~g} / \mathrm{L}$, the decrease in $R$ value gradually slowed. According to the analysis in Fig. 2, the main reason is that when the dosage was between $1 \mathrm{~g} / \mathrm{L}$ and $2 \mathrm{~g} / \mathrm{L}$, the removal amount increased the fastest, and then the rate gradually became slow; when the dosage was greater than $4 \mathrm{~g} / \mathrm{L}$, the removal amount barely increased. Clearly, with the increase in dosage, the cost increased linearly, but the increase in removal amount was less than the increase in cost, resulting in the decrease in the $\mathrm{R}$ value with the increased dosage. It can be seen from Section 3.3 and Section 3.4 that increases in irradiation time and light intensity led to the increase in the removal amount of carbamazepine and also increased the cost. However, from Fig. 10, it can be seen that the removal amount of carbamazepine per unit cost increased steadily with the increase in irradiation time and light intensity, which shows that the irradiation time and light intensity had a greater effect than cost on the removal of target pollutants by ATC. As can be seen from the surface and contour map in Fig. 10, with the increase in the stirring speed, the removal amount of carbamazepine per unit cost increased at first and then decreased. Although the operation cost was relatively low under a low stirring speed, the low stirring speed resulted in the ATC not fully contacting the target pollutant, and the reaction was not as efficient, so the removal amount of the target pollutant was lower, and the $\mathrm{R}$ value was less. Similarly, excessive stirring speed did not have a great impact on the increase in the removal amount of the target pollutant, while it brought a large amount of operation cost. The $\mathrm{R}$ value was thus also reduced.

Comparing the effects of pair-wise interactions among stirring speed, ATC dosage, irradiation time, and light intensity, it can be seen that when the dosage was increased from $1 \mathrm{~g} / \mathrm{L}$ to $4 \mathrm{~g} / \mathrm{L}$, this had the greatest impact on the $\mathrm{R}$ value, followed by irradiation time, light intensity, and stirring speed. Under the influence of dosage, the maximum value of the removal amount of carbamazepine per unit cost reached more than 2.5. However, the maximum value of removal amount of carbamazepine per unit cost could only reach 1 under the effects of pair-wise interactions among irradiation time, light intensity, and stirring speed. Under low material dosage (less than $2 \mathrm{~g} / \mathrm{L}$ ), the pair-wise interactions among irradiation time, light intensity, and stirring speed can contribute much more to the treatment efficiency than medium $(2 \mathrm{~g} / \mathrm{L}$ to $4 \mathrm{~g} / \mathrm{L})$ or high (more than $4 \mathrm{~g} / \mathrm{L}$ ) material dosage. When the dosage was low, the operation cost was relatively low, which to some extent shows that the material cost is the most important factor in the actual utilization process. Clearly, it can be seen from Section 3.1 that low dosage would also reduce the removal efficiency towards target pollutants, so it is necessary to optimize the dosage selection in the actual application process. 

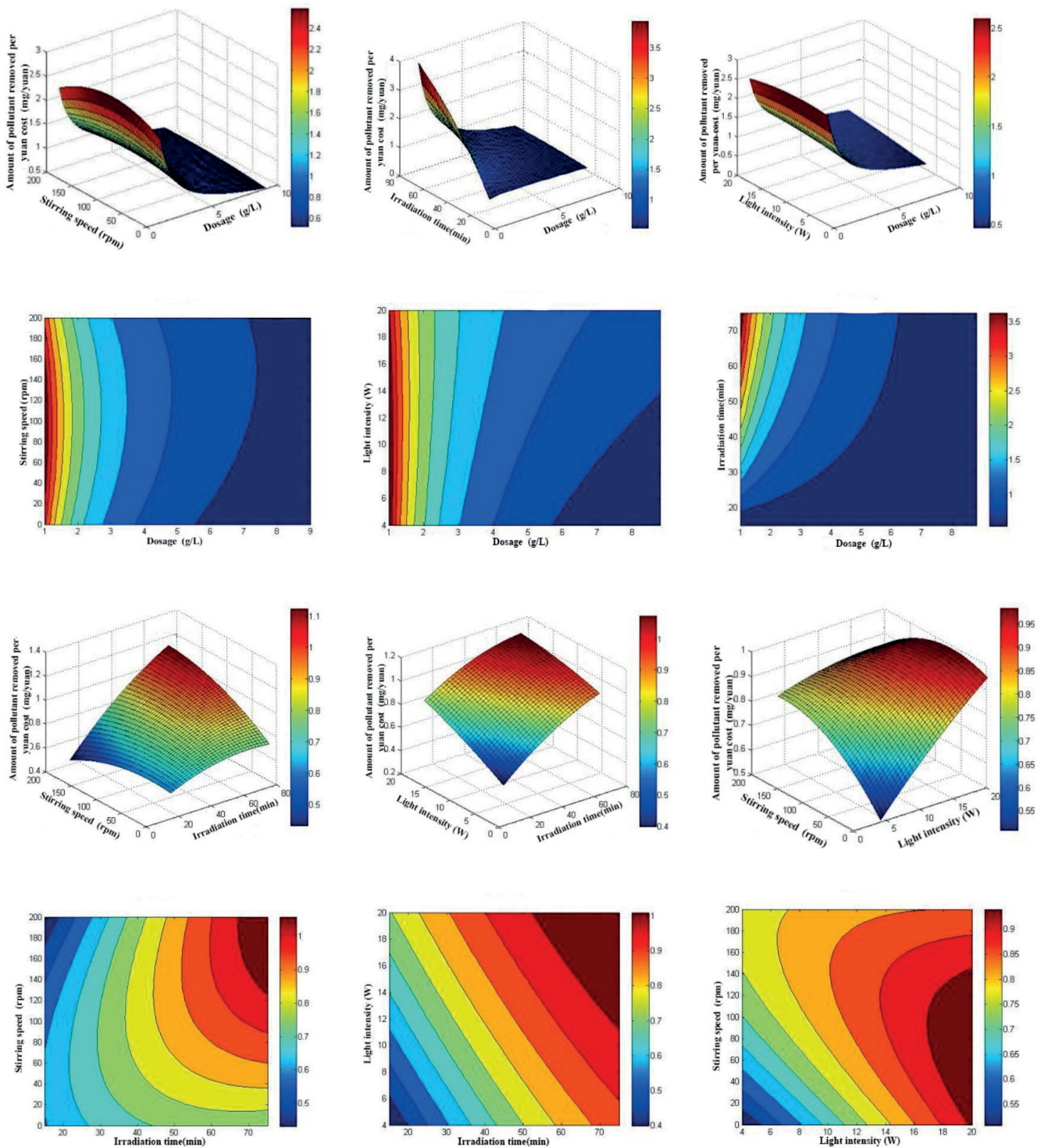

Fig. 10. Effects of interactions among stirring speed, material dosage, light intensity, and irradiation time on the removal amount of CBZ per unit cost.

According to the surface map of the effects of the interactions between irradiation time and light intensity, the surface increased uniformly and presented as a diamond shape, and the contour was evenly distributed from the lower left corner to the upper right corner, indicating that the effect of irradiation time and light intensity on the removal efficiency towards carbamazepine was relatively uniform. The number of contours on the irradiation time axis is more than that on the light intensity axis, which means that the influence of irradiation time was greater than that of light intensity. In addition, a longer irradiation time (more than $70 \mathrm{~min}$ ) and higher stirring speed (more than $160 \mathrm{rpm}$ ) or a longer irradiation time (more than $65 \mathrm{~min}$ ) and higher intensity (more than $16 \mathrm{~W}$ ) could result in a higher $\mathrm{R}$ value. By analyzing the effects the interaction between light intensity and stirring speed on the $\mathrm{R}$ value of carbamazepine, it can be seen that the number of contours on the light intensity axis was more than that on the stirring speed axis, so the influence of light intensity change was greater than that of the stirring speed. Higher light intensity (more than $18 \mathrm{~W}$ ) and moderate stirring speed (around 100rpm) could lead to higher $\mathrm{R}$ values.

\section{Conclusions}

The photocatalytic operating conditions, including stirring speed, composite material dosage, light 
intensity, and irradiation time, all had influence on the removal of carbamazepine from wastewater, in similar patterns. With an increase in each factor, the removal efficiency towards carbamazepine increased correspondingly, finally tending to be stable. After $240 \mathrm{~min}$ of continuous irradiation, the removal efficiency towards carbamazepine reached about $99 \%$.

Compared with the irradiation time, light intensity, and stirring speed, the ATC material dosage could affect the treatment efficiency significantly, which shows that material cost is an important factor in the actual process operation followed by irradiation time, light intensity, and stirring speed. Comparing the effects of pair-wise interactions, it showed that under low material dosage (less than $2 \mathrm{~g} / \mathrm{L}$ ), the pair-wise interactions among irradiation time, light intensity, and stirring speed can contribute treatment efficiency. In addition, Longer irradiation time (more than $70 \mathrm{~min}$ ) and higher stirring speed (more than $160 \mathrm{rpm}$ ) or a longer irradiation time (more than $65 \mathrm{~min}$ ) and higher intensity (more than $16 \mathrm{~W}$ ) could also lead to higher per cost treatment efficiency.

To further optimize the process, studies that investigate the effect of organic community and chemical agents added into the wastewater treatment plants in site other than the scale used in this study are recommended. In addition, the modified photocatalysis materials introduced in powder, which is inconvenient for recycling. Further investigations on friendly material recycling methods, like fixed material filling or painting, are needed to conduct. However, this study does significantly showed that removal efficiency of PPCPs is influenced by operating conditions, which can guide the photocatalysis materials effective application in the sewage plants or water supply plants. The optimal operating conditions for pollutant degradation obtained by numerical simulation can also provide support for the practical application of ATC. Finally, the cost of wastewater treatment for particular pollutants disposal can be obtained easily.

\section{Acknowledgements}

This research was supported by the National Natural Science Foundation of China (No.: 51579072; 51679102) and the Fundamental Research Funds for the Central Universities (No.: B19020074).

\section{Conflict of Interest}

The authors declare no conflict of interest.

\section{References}

1. LEE C.O., HOWE K.J., THOMSON B.M. Ozone and biofiltration as an alternative to reverse osmosis for removing PPCPs and micropollutants from treated wastewater. Water Research, 46 (4), 1005, 2012.

2. MICHAEL I., RIZZO L., MCARDELL C.S., MANAIA C.M., MERLIN C., SCHWARTZ T. Urban wastewater treatment plants as hotspots for the release of antibiotics in the environment: A review. Water Research, 47 (3), 957, 2013.

3. LI X., WANG Y., YUAN S., LI Z., WANG B., HUANG J. Degradation of the anti-inflammatory drug ibuprofen by electro-peroxone process. Water Research, 63, 81, 2014.

4. ALVARINO T., SUAREZ S., KATSOU E., VAZQUEZPADIN J.R., LEMA J.M., OMIL F. Removal of PPCPs from the sludge supernatant in a one stage nitritation/anammox process. Water Research, 68, 701, 2015.

5. ROBERTS J., KUMAR A., DU J., HEPPLEWHITE C.L., ELLIS D.J., CHRISTY A.G. Pharmaceuticals and personal care products (PPCPs) in Australia's largest inland sewage treatment plant, and its contribution to a major Australian river during high and low flow. Science of The Total Environment, 541, 1625, 2016.

6. XU R., ZHOU M., WANG H., WANG X., WEN X. Influences of temperature on the retention of PPCPs by nanofiltration membranes: Experiments and modeling assessment. Journal of Membrane Science, 599, 1, 2020.

7. MOHAPATRA D.P., BRAR S.K., TYAGI R.D., PICARD P., SURAMPALLI R.Y. Analysis and advanced oxidation treatment of a persistent pharmaceutical compound in wastewater and wastewater sludge-carbamazepine. Science of The Total Environment, 470, 58, 2014.

8. GAO X., ZHANG X., WANG Y., PENG S., YUE B., FAN C. Photocatalytic degradation of carbamazepine using hierarchical $\mathrm{BiOCl}$ microspheres: Some key operating parameters, degradation intermediates and reaction pathway. Chemical Engineering Journal, 273, 156, 2015.

9. GAO X., PENG W., TANG G., GUO Q., LUO Y. Highly efficient and visible-light-driven $\mathrm{BiOCl}$ for photocatalytic degradation of carbamazepine. Journal of Alloys and Compounds, 757, 455, 2018.

10. DENG J., SHAO Y., GAO N., ZHOU S., TAN C., HU $\mathrm{X}$. Photochemical degradation of typical pharmaceutical carbamazepine in water by $\mathrm{UV} / \mathrm{H}_{2} \mathrm{O}_{2}$ process. Journal of Central South University: Science and Technology, 9, 3933, 2013.

11. MONTEAGUdO J. M., DURÁN A., GONZÁlEZ R., EXPÓSITO A.J. In situ chemical oxidation of carbamazepine solutions using persulfate simultaneously activated by heat energy, UV light, $\mathrm{Fe}^{2+}$ ions, and $\mathrm{H}_{2} \mathrm{O}_{2}$. Applied Catalysis B: Environmental, 176, 120, 2015.

12. WANG S., ZHOU N. Removal of carbamazepine from aqueous solution using sono-activated persulfate process. Ultrasonics Sonochemistry, 29, 156, 2016.

13. YANG S., HAI F.I., NGHIEM L.D., PRICE W.E., RODDICK F.A., MOREIRA M.T. Understanding the factors controlling the removal of trace organic contaminants by white-rot fungi and their lignin modifying enzymes: A critical review. Bioresource Technology, 141, 97, 2013.

14. LIU F., ZHAO J., WANG S., DU P., XING B. Effects of Solution Chemistry on Adsorption of Selected Pharmaceuticals and Personal Care Products (PPCPs) by Graphenes and Carbon Nanotubes. Environmental Science \& Technology, 48 (22), 13197, 2014. 
15. CABRERALAFAURIE W.A., ROMAN F.R., HERNANDEZMALDONADO A.J. Transition metal modified and partially calcined inorganic-organic pillared clays for the adsorption of salicylic acid, clofibric acid, carbamazepine, and caffeine from water. Journal of Colloid and Interface Science, 386 (1), 381. 2012.

16. LIN Y., CHIOU J., LEE C. Effect of silica fouling on the removal of pharmaceuticals and personal care products by nanofiltration and reverse osmosis membranes. Journal of Hazardous Materials, 277, 102, 2014.

17. LIN Y., LEE C. Elucidating the Rejection Mechanisms of PPCPs by Nanofiltration and Reverse Osmosis Membranes. Industrial \& Engineering Chemistry Research, 53 (16), 6798, 2014.

18. BELVER C., BEDIA J., RODRIGUEZ J.J. Zr-doped $\mathrm{TiO}_{2}$ supported on delaminated clay materials for solar photocatalytic treatment of emerging pollutants. Journal of Hazardous Materials, 322, 233, 2017.

19. ZHANG X., LEI L. Effect of preparation methods on the structure and catalytic performance of $\mathrm{TiO}_{2} / \mathrm{AC}$ photocatalysts. Journal of Hazardous Materials, 153 (1), $827,2008$.

20. RIZZO L., MERIC S., KASSINOS D., GUIDA M., RUSSO F., BELGIORN,V. Degradation of diclofenac by $\mathrm{TiO}_{2}$ photocatalysis: UV absorbance kinetics and process evaluation through a set of toxicity bioassays. Water Research, 43 (4), 979, 2009.

21. GRANDCLEMENT C., SEYSSIECQ I., PIRAM A., WONGWAHCHUNG P., VANOT G., TILIACOS N. From the conventional biological wastewater treatment to hybrid processes, the evaluation of organic micropollutant removal: A review. Water Research, 111 (111), 297, 2017.

22. JELIC A., MICHAEL I., ACHILLEOS A., HAPESHI E., LAMBROPOULOU D.A., PEREZ S. Transformation products and reaction pathways of carbamazepine during photocatalytic and sonophotocatalytic treatment. Journal of Hazardous Materials, 263 (10), 177, 2013.

23. XU J., LI L., GUO C., ZHANG Y., MENG W. Photocatalytic degradation of carbamazepine by tailored BiPO4: efficiency, intermediates and pathway. Applied Catalysis B-environmental, 130 (6), 285, 2013.

24. KANG K., JANG M., CUI M., QIU P., PARK B., SNYDER S.A. Preparation and characterization of magnetic-core titanium dioxide: Implications for photocatalytic removal of ibuprofen. Journal of Molecular Catalysis A-chemical, 390 (8), 178, 2014.

25. ELHALIL A., ELMOUBARKI R., FARNANE M., MACHROUHI A., SADIQ M., MAHJOUBI F.Z. Photocatalytic degradation of caffeine as a model pharmaceutical pollutant $\mathrm{Mg}$ doped $\mathrm{ZnO}-\mathrm{Al}_{2} \mathrm{O}_{3}$ heterostructure. Environmental Nanotechnology Monitoring \& Management, 10, 63. 2018.

26. BORJI S.H., NASSERI S., NABIZADEH R., MAHVI A.H., ZARE M.R. Toxicity evaluation of phenol byproducts resulted from degradation of phenol by $\mathrm{Fe}$ (III)-doped $\mathrm{TiO}_{2} / \mathrm{UV}$ process. Desalination and Water Treatment, 82, 332, 2017.

27. KOE W.S., LEE J.W., CHONG W.C., PANG Y.L., SIM L.C. An overview of photocatalytic degradation: photocatalysts, mechanisms, and development of photocatalytic membrane. Environmental Science and Pollution Research, 27 (3), 2522, 2020.

28. KUMAR A., PANDEY G. A review on the factors affecting the photocatalytic degradation of hazardous materials. Material Science \& Engineering International Journal, 1, 1, 2017.

29. AHMADI M., VAHABZADEH F., BONAKDARPOUR B., MOFARRAH E., MEHRANIAN M. Application of the central composite design and response surface methodology to the advanced treatment of olive oil processing wastewater using Fenton's peroxidation. Journal of Hazardous Materials, 123 (1), 187, 2005.

30. KHATAEE A.R., ZAREI M., MORADKHANNEJHAD L. Application of response surface methodology for optimization of azo dye removal by oxalate catalyzed photoelectro-Fenton process using carbon nanotube-PTFE cathode. Desalination, 258 (s 1-3), 112, 2010.

31. SAHU J.N., ACHARYA J., MEIKAP B.C. Optimization of production conditions for activated carbons from Tamarind wood by zinc chloride using response surface methodology. Bioresource Technology, 101 (6), 1974, 2010.

32. VARGAS A.M., MARTINS A.C., ALMEIDA V.C. Ternary adsorption of acid dyes onto activated carbon from flamboyant pods (Delonix regia): Analysis by derivative spectrophotometry and response surface methodology. Chemical Engineering Journal, 195, 173, 2012. 